\title{
Nursing and Social Work Students' Knowledge and Attitudes Toward Patients with HIV/AIDS
}

\author{
Emory L. Perkins ${ }^{1 *}$, LCSW, ACSW, LMFT, Cordelia Obizoba ${ }^{2}$, RN, Fabio Chacon ${ }^{3}$, Derrick M. Bullock ${ }^{4}$, Javon Scoot ${ }^{1}$, \\ Kenice Brooks', Jordan Thomas ${ }^{1}$ \\ ${ }^{1}$ Department of Social Work, Bowie State University, 14000 Jericho Park Road, Maryland 20715, United States. \\ ${ }^{2}$ Assistant Professor, Department of Nursing, Bowie State University, 14000 Jericho Park Road, Maryland 20715, United States. \\ ${ }^{3}$ Division of Academic Affairs, Bowie State University, 14000 Jericho Park Road, Maryland 20715, United States. \\ ${ }^{4}$ Department of Behavioral Sciences and Human Services, Bowie State University, 14000 Jericho Park Road, Maryland 20715, United States.
}

Article Details

Article Type: Research Article

Received date: $19^{\text {th }}$ December, 2020

Accepted date: $28^{\text {th }}$ January, 2021

Published date: $30^{\text {th }}$ January, 2021

*Corresponding Author: Emory L. Perkins, LCSW, ACSW, LMFT, Assistant Professor, Department of Social Work, Bowie State University, 14000 Jericho Park Road, Maryland 20715, United States. E-mail: eperkins@bowiestate.edu

Citation: Perkins, E.L., Obizoba, C., Chacon, F., Bullock, D.M., J, Scott., Brooks, K., \& Thomas, J. (2021). Nursing and Social Work Students' Knowledge and Attitudes Toward Patients with HIV/AIDS. J Comp Nurs Res Care 6(1):167. doi: https:// doi.org/10.33790/jenrc1100167.

Copyright: (C2021, This is an open-access article distributed under the terms of the Creative Commons Attribution License 4.0, which permits unrestricted use, distribution, and reproduction in any medium, provided the original author and source are credited.

\begin{abstract}
Patients living with HIV/AIDS are marginalized in health care, despite the core values of the profession. Knowledge and attitudes of nursing and social work undergraduate students at a Historically Black College and University (HBCU) toward patients living with HIV/AIDS was the objective of this exploratory quantitative study. A convenience sample of 142 undergraduate nursing and social work students at a public HBCU in the US Mid-Atlantic region completed a self-administered questionnaire. Data collected were analyzed with the latest version of SPSS statistics. Results showed for matriculating students in the two majors; inadequate knowledge of HIV/AIDS, no significant difference in the level of knowledge, and that attitudes regarding the chronic disease phenomenon were generally positive without an observable change. Implications of the study indicates a critical gap in the undergraduate curriculum for nursing and social work students. Developing an elective course in HIV/AIDS for both disciplines would alleviate the knowledge gap.
\end{abstract}

Keywords: HIV/AIDS, HIV/AIDS knowledge and attitudes, nursing, social work, and cognitive dissonance theory

\section{Introduction}

AIDS, the advanced stage of the HIV infection, is a global health problem with no effective cure. According to the Centers for Disease Control (CDC) and Prevention, HIV Surveillance Report [1]there were about 1.2 million new cases of HIV in 2017 worldwide. About 36.9 million people are living with HIV around the world [2]. Nurses and Social Workers are essential part of the patient care team, caring for a variety of patient population. Social work and Nursing educational curriculum are competency-based practice professions that play major roles in the care of people living with HIV/AIDS (PLWHA). The curriculum of both disciplines integrates theoretical and clinical training processes. The theoretical knowledge and clinical skills are progressive at different levels of education based on course level objectives.

Through the situated cognition approach of clinical experiential learning, students in both disciplines are actively involved in the learning experiences in simulated laboratory and real-world patient care settings a community of practice that focuses on learning by doing. In this way, learning occurs occurs from the interaction of the learner in an environment specifically constructed to facilitate the experiences [3]. Similarly, [4] affirmed that situated learning occurs with social interactions and iterative critique by instructors and peers.
Theoretical and situated clinical learning experiences in both disciplines must equip students with the knowledge, skills, and abilities that entry-level baccalaureate graduates will need to deliver high quality, safe, effective, holistic, and focused patient care. Upon graduation, while nurses provide direct care to restore patients to health, teach health promotion, and participate in disease- prevention activities [5]. The NASW Policy on HIV and AIDS clearly states "the social work profession should take an active stand to mitigate the overwhelmingpsychologicaland socialeffects, includingtheinequality of access to health and mental health care and the lack of education and prevention in the United States and internationally."(NASW, 2009-2011)[6]. Nurses are positioned to contribute to and lead the transformative changes that are occurring in healthcare by being a fully contributing member of the inter-professional team [7]. Today's nursing and social work students are among the future health care professionals of PLWHA and consequently, their knowledge about the disease and their attitudes toward PLWHA can have an impact on their effectiveness in the delivery of care and services.

In its fourth decade, HIV/AIDS has shifted from a death sentence to chronic and manageable disease due to remarkable advancement in medication but remains a persistent health problem around the world [8]. Since the introduction of antiretroviral therapy (ART) in 1987, Forsythe, et al [9], stated significant improvements in treatment for people living with HIV and emphasized the importance of reinforcing both treatment and prevention.

Health care professionals, including nurses and social workers in health care settings, have essential roles in the care of PLWHA. Consequently, both social work and nursing curricular efforts, as well as practicum settings, must focus on the development of knowledge, skills, and unbiased attitudes for the best patient outcomes.

Social workers have an ethical responsibility to each client and are often the first line of defense for marginalized individuals who face physical, psychosocial, or socioeconomic challenges $[10,11]$ Additionally, Chandran, et al [12] noted that social work education is grounded in values of service, social justice, dignity and worth of the individual, the importance of human relationships, integrity, and competence. Social Workers are professionally obligated to live these values in their face-to-face interactions in their practice with a marginalized population (Chandran, p.340) [12], such as PLWHA. Thus, it is paramount that social work students/social workers are informed,knowledgeable and skillful in their approach when working with individuals diagnosed with HIV/AIDS. 
Nursing students are educated to provide quality health care to all patients. Graduates of both professions are generally the first among health care providers to encounter a patient living with HIV/AIDS. Social Workers have had significant involvement in the HIV response [13]. Similarly, Edmonds, et al. [14] noted that social workers have helped people cope with HIV diagnoses since the earliest days. At every stage of the HIV care continuum, social worker-involvement with HIV-positive patients is central to achieving viral suppression. In collaboration with social workers, nurses' roles in HIV management involve health promotion and disease prevention [13]. The Performance of these roles requires knowledge regarding HIV disease so that nurses can offer effective and compassionate care to patients, alleviating physical, emotional, social, and spiritual suffering at all stages of HIV disease (p.353). Additionally, Eustace [15], emphasizing HIV/AIDS family- focused prevention and management strategies, noted that nurses should be proactive in advocating for HIV/ AIDS family intervention and HIV/ AIDS family policies to improve outcomes in family functioning, processes, and relationships.

As members of the helping professions, nurses and social workers both pledge to protect the public in providing healthcare services. Possessing a highly positive attitude toward PLWHA is, therefore, essential for professionally meeting the healthcare needs of patients. Nevertheless, the achievement of such an attitude is not always the case. Dharmalingan, et al. [16] found that negative attitudes about HIV/AIDS among nursing students and other health care providers likely contribute to the prevalence of healthcare disparities among PLWHA. Notably, clinical exposures introduce nursing students to the art of caring for patients with various disease processes and allow opportunities to improve their attitudes toward those patients [15]. Baytner-Zamir, et al. [17], shared that students who had more practice or personal experience with HIV/AIDS had better attitudes regarding the care of the patients, and were more willing to care for PLWHA than those without experience. For example, through clinical experiences and contact with PLWHA, Baytner-Zamir et al. [17], noted that there were persistent misconceptions among medical students, mostly regarding HIV transmission via breastfeeding and knowledge of HIV prevention, following exposure to the virus. Many of the students' attitudes included stigmatization, shame, and fear [18]. Overall, no positive changes in students' attitudes were observed during the preclinical years of medical school; these results from the medical students were similar to those of social work and nursing students [18]. As future health care professionals, nursing and social work students' attitudes toward PLWHA must embrace a well-informed and positive approach to the care of PLWHA [16,17].

Stigma and discrimination have long been associated with HIV/AIDS and experienced by PLWHA [19]. HIV/AIDS stigma, discrimination, and resulting fears around disclosure remain key barriers to effective care and disease prevention [20-24]. Stigmatization and discrimination themes from the aforementioned studies include: (a) negative attitudes, fear of contagion, and misperceptions about transmission; (b) acts of discrimination in the workplace and by families, friends, and health care providers; and, (c) participants' use of self-isolation as a coping mechanism for responding to the stigma. Social workers and nurses can challenge such stigma and support PLWHA by focusing on therapeutic relationships, building rapport, and creating non-judgmental therapeutic environments [23,25].

As noted, adequate HIV/AIDS knowledge among health care providers including nursing and social work students, is one of the leading focal points for improved positive attitudes, reduced stigma, and better health outcomes for PLWHA. This study compares social work and nursing students' knowledge and attitudes toward PLWHA while studying at a public HBCU in the State of Maryland.

The significance of this study informs all helping professionals, including social workers and nurses, about health care outcomes for PLWHA impacted by the acquired knowledge and attitudes displayed within their professions. This study also examines how expected improvements in knowledge development and attitudes can affect the outcomes of patient and client care of PLWHA, using the
Cognitive Dissonance Theory (CDT) framework, which measures the students' cognitive discrepancies of attitudes and knowledge and the expected outcomes, according to Festinger's [26], as cited by Hinojosa, et al [27]:

The core framework of CDT implies a four-step process of dissonance arousal and reduction. First, a cognitive discrepancy occurs; second, individuals respond with psychological discomfort-dissonance; third, they become motivated to reduce the dissonance; and fourth, they engage in discrepancy reduction to reduce dissonance. It is important to note that to effectively resolve dissonance, individuals must engage in some form of discrepancy reduction; however, some people may not successfully resolve dissonance and as such, may remain in a negative affective state (p.173).

Timmins and De Vires [28] noted that cognitive dissonance theory adds considerable insight into an issue that haunts contemporary health care. Social workers do experience cognitive dissonance; they are adversely impacted by the conflicts, and they find ways to reconcile the cognitive dissonance [29]. Similarly, Daniel [30] stated that the feeling of estrangement in psychiatric nursing practice expressed by some nursing staff could be explained theoretically through the concept of cognitive dissonance.

Timmins and De Vires [28]concluded that understanding the dissonance cognitions and the reduction mechanism might help prevent care erosion and its devastating impact. The authors emphasized that ignoring, denying, trivializing and justifying of substandard practice are not appropriate ways of reducing dissonance.

\section{Problem and Hypotheses}

The researchers wanted to determine if there were changes in the adequacy of HIV/AIDS knowledge, negative attitudes, and elements of stigmatization through time. This has profound curriculum implications; to that effect, they formulated the following hypotheses:

1. College students' attitudes toward the care of HIV/AIDS patients significantly improve according to their educational attainment.

2. Students' knowledge of HIV/AIDS significantly improves according to their educational attainment.

3. Social Work students are more knowledgeable about HIV/AIDS than nursing students are.

4. Social Work students have better attitudes toward HIV/AIDS patients' care than nursing students do.

\section{Method}

\section{Research Design}

Data were collected using a cross-sectional survey to examine social work and nursing students' knowledge and attitudes about HIV/AIDS patients. As in a typical exploratory quantitative study, researchers took concurrent samples of students at different academic levels instead of following the evolution of individual students. Then, they performed a descriptive analysis and comparison of means for knowledge and attitude indicators between discipline groups and academic level groups. An assumption was that the formation of knowledge and attitudes (dependent variables) had already occurred; therefore, the researchers could measure the differences between groups according to the independent variables major and attainment level). Researchers also assumed that senior-level nursing and social work students would demonstrate expert or quasi-expert knowledge and strong positive attitudes toward providing care to HIV/AIDS patients. The participants for this study were recruited from Bowie State University, College of Professional Studies.

\section{Sampling Procedures}

The participants included a random sample of 142 students, ages 18-49. Researchers received IRB (Institutional Review Board) approval. Students were selected at random from pre-existing classes. They gave their informed consent and agreed that participation wasvoluntary and confidential. Additionally, 49 social work students 
participated in the study, while 78 nursing students participated. Data Collection Procedures

Researchers measured the dependent variables through selfassessment scales that were completed by each subject over four weeks. The researchers trained and oriented undergraduate students on how to conduct and administer the research instruments; the surveys were distributed and completed with pencils. The Knowledge Scale, HIV-KQ-45, was previously used by Carey and Schroder [31] with reliability in different samples of Cronbach alpha $=.75$ to .89 . The Attitude Scale was a modified version of the one used by Aggarwal et al., [20], covering aspects of (a) blame for getting AIDS; (b) type of hospital care for patients who are HIV positive; and (c) equal/ unequal rights of AIDS patients. The determined Cronbach alpha is .82. Eleven items on demographics included: age, date of birth, gender, race, ethnicity, academic classification, residency status, employment status, student status, and whether one had children and how many. The researchers were granted permission from four professors to survey students in their courses. The participants were informed that their participation was voluntary and confidential and that they would receive an incentive for participation (raffle). Only participants who met the eligibility criteria of being at least 18 years old were allowed to participate in this study. The researchers used alphanumeric identification codes in the instruments to ensure tracking and the protection of the privacy of the participants; data were pre-coded in Excel, and then transferred to SPSS for analysis.

\section{Data Analysis Procedures}

The analysis occurred in two stages as delineated below:

1. Descriptive analysis in the form of tables of frequencies, percentages, and means. These data allowed the researchers to observe contrasting and converging patterns in variables within, across, and among subgroups.

2. Hypothesis testing, with alpha set at 0.01 . Two contrasts of means were carried for the academic level of students (freshman, sophomore, junior, senior) and for students majoring in Social Work and Nursing.

\section{Results}

\section{Sample Demographics}

The study sample consisted of $142 \mathrm{HBCU}$ students majoring in social work and nursing, ages 17 to 49 with a mean of 24 . The proportions were $49(48.5 \%)$ social work and 78 (54.9\%) nursing. There were 50 students, aged 17-21, 13 students, aged 22-17, and 13 students among the age group of 34-39 and 40-49. The gender split was $88 \%$ females and $12.2 \%$ males. The racial composition of the sample was $83.3 \%$ Black; Asian and Whites were $4 \%$ each group; 7\% were American Indian or Alaskan Native and Native Hawaiian or Pacific Islanders, and $9.1 \%$ did not identify their race. Based on long- term experience with these programs, the researchers can state that the sampling was comprehensive and included typical students in these programs. In identifying academic classifications, $33.8 \%$ of the participants were sophomores and seniors, while $8.3 \%$ of the participants were freshman and $21.8 \%$ were juniors.

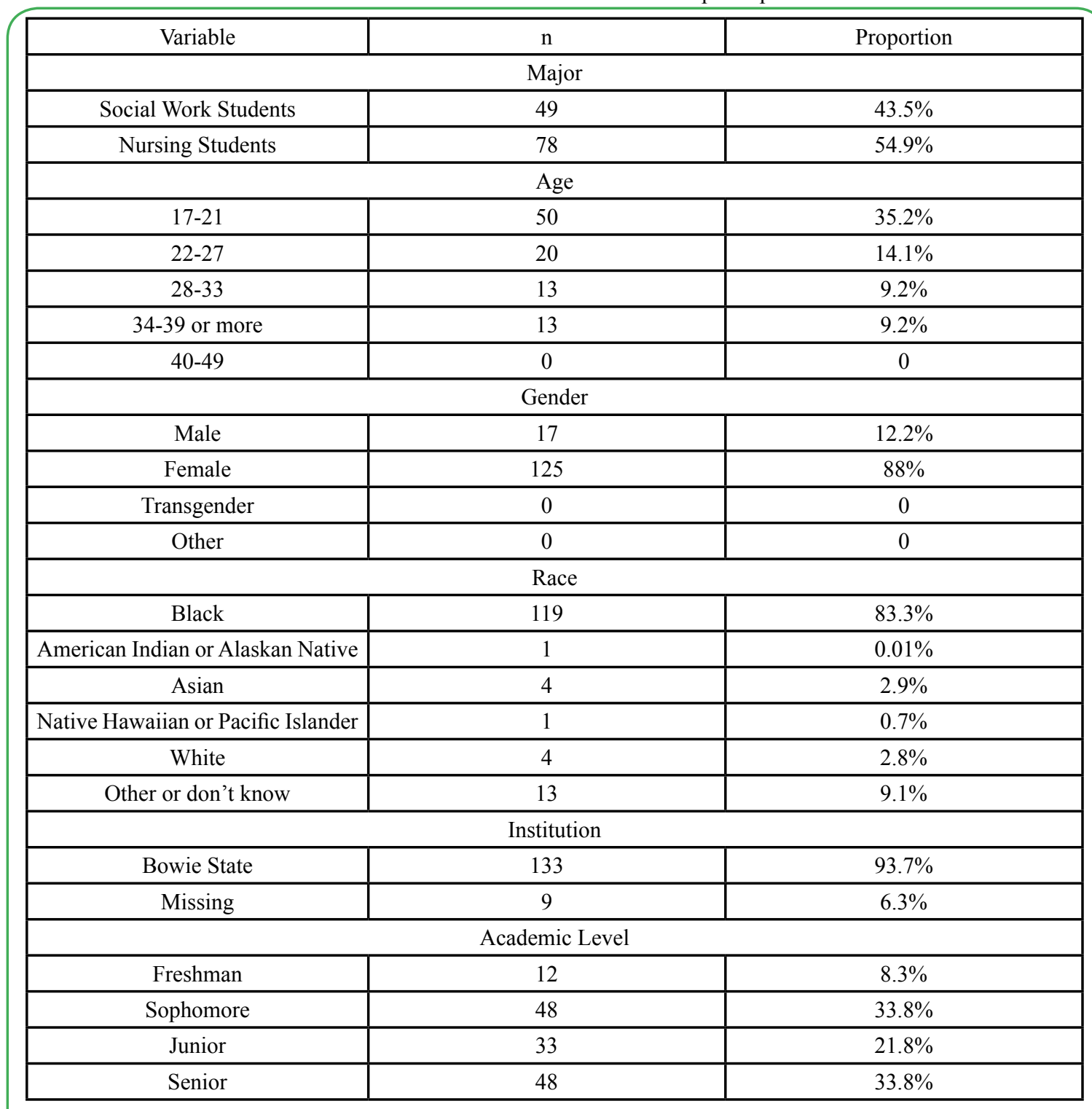

Table I . Demographic Variables 


\section{Dependent Variables}

HIV knowledge and attitudes about AIDS patients are two important aspects of social work and nursing programs of study as they are included in several courses, although taught separately and by different professors. Nursing includes courses such as Health Assessment and Care of Complex Clients; Social Work includes the topic in Social Research and Community Service courses. The typical methods of assessing outcomes about HIV/AIDS in both programs are tests for knowledge review and case studies. Students are expected to excel in both areas by the end of their period of formation as they may encounter many cases in their jobs. Descriptive results, summarized in Table 2, indicated that social work (SW) students had a better knowledge score than nursing (NU) students in a 60-point test, $\mathrm{SW}$ mean $=34.61$ vs. $\mathrm{NU}$ mean $=34.10$ but this difference is not significant. The test used is True/False and combines scientific and stereotypical statements about HIV; it must be noticed that in both groups the mean is just above half the scale - meaning they are far from scoring at the expert level. The Likert attitude scale contained 57 statements about AIDS patients and AIDS patients care, and student would show agreement or disagreement in 5 points; the highest indicating a positive attitude and the lowest a negative attitude. Results show no significant difference between the mean score of social work, 4.58 points, and nursing, 4.61 points; both groups evidenced mostly positive attitudes toward AIDS patients. In addition, the variable distributions are similar to the normal, not skewed.

\begin{tabular}{|l|l|l|}
\hline Variable & Mean & Standard Deviation \\
\hline HIV Knowledge: (Max Possible $=60)$ & 44.62 & 4.3 \\
\hline Social Work & 34.13 & 3.5 \\
\hline Nursing & 4.58 & 1.2 \\
\hline AIDS Attitude Scale: (Max Possible $=5)$ & 1.3 \\
\hline Nursing & 4.61 & \\
\hline Social Work & \multicolumn{2}{|l|}{} \\
\hline
\end{tabular}

The hypothesis testing, Table 3, allows the following major conclusions:

shows non-significant variations: First Year $=4.72$, Second Year $=$ 4.58, Third Year $=4.52$ and Fourth Year $=4.65$. The F (3.49) $=0.497$

1. Attitudes of students significantly improve according to their years attending a HBCU. A One-way ANOVA of the means failed to reject the null hypothesis. Attitudes are generally positive and do not vary much through the academic years.

\begin{tabular}{|l|l|l|l|}
\hline Research Hypotheses & H-Test & Sig. $<0.01$ & Conclusion \\
\hline $\begin{array}{l}\text { H1: Attitude of students significantly improves according to } \\
\text { their years of attending Bowie State University. }\end{array}$ & $\mathrm{F}(3,49)=0.497$ & N/A & Not supported \\
\hline $\begin{array}{l}\text { H2: Knowledge of students significantly improves according } \\
\text { to their years of attending Bowie State University. }\end{array}$ & $\mathrm{F}(3,49)=4.313$ & $<0.01$ & Supported \\
\hline $\begin{array}{l}\text { H3: Social Work students have more knowledge about HIV/ } \\
\text { AIDS than Nursing students do. }\end{array}$ & $\mathrm{t}(48)=-0.305$ & N/A & Not Supported \\
\hline $\begin{array}{l}\text { H4: Social Work students have better attitudes toward HIV/ } \\
\text { AIDS patients than Nursing students do. }\end{array}$ & $\mathrm{t}(48)=0.466$ & N/A & Not Supported \\
\hline
\end{tabular}

2. The Knowledge about HIV of students significantly improves according to their years of attending Bowie State University. The One-way ANOVA test of this hypothesis is seen in Table 4. The means of knowledge in the whole sample for each year

were the following: First- Year $=32.75$, Second Year $=34.48$, Third Year $=32.55$ and Fourth Year $=36.69 ; \mathrm{F}(3,49)=4.313$, Sig. $<0.01$. The null hypothesis is rejected, and the means show an improvement of knowledge through the years.

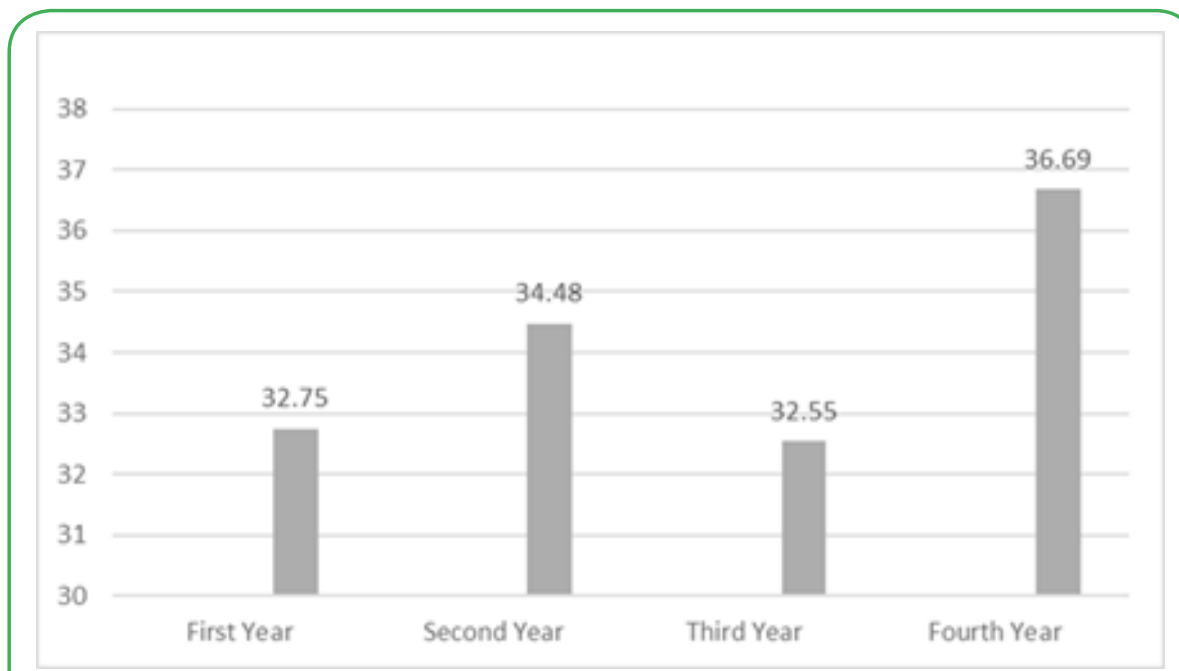

Figure 1. Bar chart showing means of HIV-Knowledge for groups corresponding to number of years in college 
3. The Attitude about AIDS patients of students significantly improves according to their years of attending Bowie State University. An independent-samples t-test was used for this hypothesis. The means of knowledge for Social Work was 4.58 and for Nursing 4.61. The $t(48)=-0.305$ and it is nonsignificant, therefore, the two means are assumed equal.

4. Social work students have better attitudes toward HIV/AIDS patients than nursing students do. An independent-samples $\mathrm{t}$-Test was used for this hypothesis. The mean of knowledge for Social Work was 34.61 and for Nursing 34.13. The t $(48)=0.466$, non-significant, therefore, the two means are assumed equal.

In a further analysis, the researchers considered whether the two dependent variables might be highly correlated, which would generate confounding results because it would be difficult to distinguish the effects of the independent variables from any of the dependent variables. It was found that the Pearson Correlation Coefficient between attitude and knowledge is 0.3 (low) and Sig. < 0.01 . There is just a small likelihood of confounding results, as the correlation between dependent variables is low.

\section{Discussion}

Nursing and Social Work students have similar knowledge about HIV and attitudes toward the treatment of AIDS despite their assumedly differentiated training. Attitudes are more on the positive than negative side and they do not change through the years of study. Knowledge about HIV improves significantly through the years of study (Table 4) but does not reach high standards of competency as would be expected of nursing and social work graduates. The expected mean would be at least 56 out of a maximum of 70, which is equivalent to a grade of B in the scale of Bowie State University. These outcomes suggest a potential cognitive dissonance when students face real cases of HIV/AIDS in their work; they are trained to react positively but do not have sufficient knowledge to respond with best practices of care toward the patients. This would generate an attraction-avoidance conundrum with negative consequences for the treatment of patients. The expected professional behavior is just the opposite: a well-trained professional that applies best practices of care and safety measures, mediated by a highly positive attitude to the patient.

\begin{tabular}{|l|l|l|l|l|l|}
\hline Source & Sum of Squares & df & Mean Square & F-ratio & Sig. \\
\hline Between Groups & 380.889 & 3 & 126.963 & 4.313 & .006 \\
\hline Within Groups & 3974.219 & 135 & 29.439 & & \\
\hline Total & 4355.108 & 138 & & & \\
\hline
\end{tabular}

Table. 4 Analysis of Variance (ONEWAY) between Years of College and HIV-Knowledge

\section{Limitations of the Study}

There are limitations to this study. Since the framework established for providing care to HIV/AIDS patients centered on an examination of the knowledge and attitudes of nursing and social work majors, the results of the study may not be generalizable to other students in other disciplines. A larger and more inclusive sample with more males and students of other majors would be needed. A small sample size limits the generalizability of the study. A second limitation of the study is the use of closed-ended questions. There should be open- ended questions to explore different aspects of knowledge and attitude.

\section{Implications for Future Research}

The findings from this investigation indicate that Knowledge and Attitudes about HIV/AIDS show a critical gap in the curriculum of Nursing and Social Work undergraduate students. It would be convenient to study how widespread this gap is in other colleges and universities. An assessment would provide guidelines for curriculum design and practice involving the training of students in this area. In addition, it would be convenient to analyze if other independent variables, such as student gender, socio-economic status and financial aid designation of recipient/non recipient, have an impact.

Regional and national studies are needed, specifically conducted by social work and nursing educators, to explore investigating the need to infuse content into the curriculum, aimed at training nursing and social work students in HBCUs to become culturally competent and sanative in providing care to HIV/AIDS patients.

In summary, the researchers, namely social work and nursing educators in HBCUs, must develop a course in HIV/AIDS, which addresses the disease across the life span. This is especially important since the CDC acknowledged that at the end of 2016, 478,100 Black/African American had been given an HIV diagnoses, (CDC, 2016) [32]. Additionally, the CDC reported that in 2018, adult and adolescent Blacks/African Americans accounted for more than $42 \%$ of all newly diagnosed HIV cases in the United States. Of those more than $42 \%, 31 \%$ of those cases were Black/African American men and $11 \%$ were Black/African American women (CDC, 2016) [32].

\section{Implications for Policy}

According to the CDC, African Americans comprised up to $42 \%$ of all reported HIV cases in the United States in 2017 (CDC, 2017),[32] even though African Americans comprised only $12.6 \%$ of the United States population (US Census, 2010). According to CDC (2017), there were 1.1 million PLWHA in the United States at the end of 2017. HIV remains a significant cause of death target populations. HIV was reported the 9th leading cause of death for persons aged 25 to 34 and the 9th cause of death for persons aged 35 to 44 (CDC, 2017)[32]. However, HIV cases continue to decrease among all African-Americans in the United States (CDC, 2017)[32]. CDC (2017) continues to maintain, however, that African-American men, women, and adolescents continue to be disproportionately affected by HIV/AIDS. For aspiring students in the helping professions, like nursing and social work, there must be comprehensive curriculum policies developed at the university level to address this issue.

HBCU presidents and administrators must be open to discussing HIV/AIDS in general and be receptive to allowing faculty to develop and implement curricula aimed at addressing this pandemic as an educational goal for all students. There is urgency to include this educational goal in the curriculum, given how HIV/AIDS is decimating African American communities.

There must be state appropriation of funds to develop and collaborate with local and state agencies to implement evidence-based behavioral and educational models that will provide African-Americans and all students with basic facts and information on how HIV/AIDS is and is not transmitted. Additionally, the state must appropriate funds to develop/implement a required general education course for all students. This required general education course will prepare nursing and social work students with the skills and knowledge needed to provide culturally competent care to those persons infected and affected with HIV/AIDS

\section{Contributions to Social Work Education}

Results from this study support the integration of incorporating more HIV/AIDS content in social work education. Social work and nursing students were equally knowledgeable about HIV/AIDS and their attitudes toward patients with the disease were mostly positive, which did not change through the years of study. The research findings from this investigation will support the development of culturally competent interventions. It is anticipated that the findings from this investigation will assist with the development of a practice model and a course on 
HIV/AIDS required for all students, and especially for nursing and social work majors, at HBCUs.

Given the pervasiveness of the disease, the infusion of HIV/ AIDS information throughout the nursing and social work curricula should be mandatory for accredited schools of nursing and social work. It is important for schools of nursing and social work to fully operationalize and make a commitment and obligation to infuse HIV/AIDS content throughout the curriculum to enhance student knowledge and attitudes toward PLWHA.

Conflict of interests: The authors declare no conflict of interest.

\section{References}

1. Centers for Disease Control and Prevention. HIV Surveillance Report, 2017; vol. 29. http://www.cdc.gov/hiv/library/reports/ hiv-surveillance.html. Published November 2018. Accessed (July 2019).

2. Yoshimura, K. (2017). Current status of HIV/AIDS in the ART era. Journal of Infection and Chemotherapy, 23(1), 12-16. https://doi.org/10.1016/j.jiac.2016.10.002

3. Johnston, E., Olivas, G., Steele, P., Smith, C., \& Bailey, L. (2018). Exploring Pedagogical Foundations of Existing Virtual Reality Educational Applications: A Content Analysis Study. Journal of Educational Technology Systems, 46(4), 414-439.

4. Gomez, K., \& Lee, U.-S. (2015). Situated Cognition and Learning Environments: Implications for Teachers On and Offline in the New Digital Media Age. Interactive Learning Environments, 23(5), 634-652

5. Keeling, A. W., Hehman, M. C., \& Kirchgessner, J. C. (2017). History of Professional Nursing in the United States: Toward a Culture of Health. Springer Publishing Company

6. Social Work Speaks, National Association of Social Workers Policy Statements 2009-2012, 8th Edition, HIV and AIDS, pp. 171-176.

7. Salmond, S. W., \& Echevarria, M. (2017). Healthcare Transformation and Changing Roles for Nursing. Orthopedic Nursing, 36(1):12-25. https://doi.org/10.1097/ NOR.0000000000000308

8. Silva, A. F., \& Cueto, M. (2018). HIV/AIDS, its stigma and history. História, Ciências, Saúde-Manguinhos, 25(2), 311-314. https://doi.org/10.1590/s0104-59702018000200001

9. Forsythe, S. S., McGreevy, W., Whiteside, A., Shah, M., Cohen, J., Hetcht, R., \& Kinghorn, A. (2019). Twenty Years of Antiretroviral Therapy for People Living With HIV: Global Costs, Health Achievements, Economic Benefits. Global Health Policy, 38(7), 1163-1172. https://doi.org/10.1377/ hlthaff.2018.05391

10. Hernandez, J. P., \& McGowan, M. J. (2015). Psychosocial interventions for women with HIV/AIDS: A critical review. Research on Social Work Practice, 25(1), 103-116

11. Watkins, D. C., Hawkins, J., \& Mitchell, J. A. (2015). The discipline is escalating whisper: Social work and black men's mental health. Research on Social Work Practice 25(2), 240-250

12. Chandran, D. (2016). Social media and HIV/AIDS: Implications for SocialWorkEducation.Social WorkEducation, 35(3), 333-343

13. Hampton, G., Buggy, M., Graves, J., McCann, L., \& Irwin, J. (2017). Grappling with realities: Policy and practice in HIV social work. Australian Social Work, 70(1), 92-103

14. Edmonds, A., Moore, E., Valdez, A., \& Tomlinson, C. (2015). Social work and the HIV care continuum: Assisting HIV patients diagnosed in an emergency department. Social Work, 60(3), 238-246

15. Eustace, R. W. (2013). A discussion of HIV/AIDS family interventions: Implications for family-focused nursing practice. Journal of Advanced Nursing, 69(7), 1660-1672
16. Dharmalingan, M., Poreddi, V., Gandhi, S., \& Chandran, R. (2015). Undergraduate nursing students' knowledge and attitude toward people living with human immunodeficiency virus/ acquired immunodeficiency syndrome. International Journal of Advanced Medical and Health Research, 2(1), 22-27. https:// doi.org/10.4103/2349-4220.159124

17. Baytner-Zamir, R., Lorber, M. \& Hermoni, D. Assessment of the knowledge and attitudes regarding HIV/AIDS among pre-clinical medical students in Israel. BMC Res Notes 7, 168 (2014). https://doi.org/10.1186/1756-0500-7-168

18. Kale, M., Gholap, M., \& Shinde, M. (2014). A study to assess knowledge, attitude, and practices offivemomentsofhand hygiene among nursing staffand students at a tertiary care hospital at Karad. International Journal of Science and Research, 3(2), 311-321

19. Bowen, E. (2013). AIDS at 30: Implications for social work education. Journal of Social Work Education, 49 (2), 265-276.

20. Aggarwal, S., Lee, D. H., Minteer, W. B., Fenning, R. T., Raja, S. K., Bernstein, M. E., Diamond, C. A. (2017). Another Generation of Stigma? Assessing Healthcare Student Perceptions of HIVPositive Patients in Mwanza, Tanzania. AIDS Patient Care and STDs, 31(2), https://doi.org/10.1089/apc.2016.0175

21. Audet, C. M., McGowan, C. C., Wallston, K. A., \& Kipp, A. M. (2013). Relationship between HIV Stigma and Self-Isolation among People Living with HIV in Tennessee. PLOS ONE, 8(8), e69564. http://doi.org/10.1371/journal.po ne.0069564

22. Farotimi, A. A., Nwozichi, C. U., \& Ojediran, T. D. (2015). Knowledge, attitude, and practice of HIV/AIDS-related stigma and discrimination reduction among nursing students in southwest Nigeria. Iran Journal Nursing Midwifery Research, 20(6), 705-711. https://doi.org/10.4103/1735-9006.170011

23. Foreman, M., \& Ni Rathaille, N. (2016). Not just another LongTerm Chronic Illness-Social Work and HIV in Ireland. Practice. Social Work in Action, 28(2), 97-114

24. Paudel, V., \& Baral, K. P. (2015). Women living with HIV/AIDS (WLHA), battling stigma, discrimination and denial and the role of support groups as a coping strategy: A review of literature. Reproductive Health, 12: 53. http://doi.org/10.1186/s12978015-0032-9

25. Orellana, E. R., Goldbach, J., Rountree, M. A., \& Bagwell, M. (2015). Access to mental health and substance abuse services by people living with HIV/AIDS: The case manager perspective. Health \& Social Work, 40(2), e10-e14

26. Festinger, L. (1957). A Theory of Cognitive Dissonance. Stanford University Press

27. Hinojosa, A. S., Gardner, W. L., Walker, H. J., Cogliser, C., \& Gullifor, D. (2017). A review of cognitive dissonance theory in management research: Opportunities for further development. Journal of Management, 43(1), 170-199. https://doi.org/ doi $/ 10.1177 / 0149206316668236$

28. Timmins, F., and De Vries, J. (2016). Care erosion in hospitals: Problems in reflective nursing practice and the role of cognitive dissonance. Nurse Education Today, 38:5-8.

29. Burke, S., Schmidt, G., Wagner, S., Hoffman, R., \& Hanlon, N. (2017). Cognitive Dissonance in Social Work. Journal of Public Child Welfare, 11(3), 299-317.

30. Daniel, J. J. (2014). Understanding the domestic rupture in forensic psychiatric nursing practice. Journal of Correctional Health Care, 20(1), 45-58

31. Carey,M.andSchroder,K.(2002).DevelopmentandPsychometric Evaluation of the Brief HIV Knowledge Questionnaire. AIDS Education and Prevention, 2002 Apr; 14(2): 172-182

32. Centers for Disease Control and Prevention. HIV Surveillance Report, 2016; vol. 28. http://www.cdc.gov/hiv/library/reports/ hiv-surveillance.html. Published November 2017. 